\title{
A influência da religião na atuação de Damares Alves na Organização das Nações Unidas (ONU)
}

\author{
The influence of religion in the performance of Damares Alves at the \\ United Nations (UN)
}

\author{
Jordana de Moraes Neves ${ }^{\mathrm{a}} \odot$, Rafael de Oliveira Wachholz ${ }^{\mathrm{b}} \odot$
}

Resumo $\mathrm{O}$ presente artigo apresenta uma análise da relação entre religião e esfera pública no Brasil contemporâneo. Para isso, observa-se a influência da filiação religiosa de Damares Alves na agenda do Ministério da Mulher, da Família e dos Direitos Humanos por ela comandado, contextualizando-a como expoente de uma ascendente Direita Cristã na política nacional. O texto é metodologicamente baseado na averiguação documental de oito discursos proferidos pela ministra enquanto representante do Brasil na ONU, coletados via Lei de Acesso à Informação. Problematiza-se de que maneira os valores religiosos da ministra se relacionam com os constrangimentos de uma esfera social pautada por regras laicas e seculares. Conclui-se que uma possível defesa de valores religiosos de Damares é constrangida pela institucionalidade do cargo e da instância de debate, ainda que seja possível vislumbrar a influência de seu posicionamento religioso em algumas posições sustentadas em seus discursos.

Palavras-chave Religião. Direita Cristã. Damares Alves. ONU. Secularização.

\begin{abstract}
This article presents an analysis on the relation between Religion and public sphere in Brazil. It analyses the influence of Damares Alves' religious filiation on the Woman, Family and Human Rights Ministry that she commands, contextualizing her as an exponent of an ascending Christian Right. The paper is methodologically based on documental analysis of eight speeches given by the Minister as Brazil's representative at the UN, collected by the 'Lei de Acesso à Informação'. It debates how the Minister's religious values relate to the constraints of a laique and secular social sphere. It concludes that a possible defense of religious values is constrained by the institutionality of Damares Alves role as State Ministry and also by the debate stance, though it is possible to visualize the influence of her religious values in some statements sustained on her speeches.
\end{abstract}

Keywords Religion. Christian Right. Damares Alves. UN. Secularization.

a Doutoranda no Programa de Pós-Graduação em Ciências Sociais da UFSM; Mestre em Sociologia no Programa de Pós-Graduação em Sociologia da UFRGS e Bacharel em Ciências Sociais pela UFSM. E-mail: jordana.neves@hotmail.com

b Mestre em Ciências Sociais pelo Programa de Pós-Graduação em Ciências Sociais da UFSM; Bacharel em Relações Internacionais pela Universidade Federal de Santa Maria - UFSM. E-mail: rafaeldeoliveiraw@gmail.com 


\section{INTRODUÇÃO}

O mercado religioso brasileiro tem sido marcado nas últimas décadas por uma diversificação no que tange às estratégias de inserção das religiões na esfera pública, especialmente a política. Este processo vem sendo representado, por exemplo, pelo crescimento da chamada Frente Parlamentar Evangélica no Congresso Nacional, cujos atores, não coincidentemente, ocuparam lugar de destaque em postos de alto escalão no governo federal corrente, presidido por Jair Bolsonaro. Do ponto de vista prático, estes elementos têm suscitado tensionamentos no âmbito político e também têm motivado importantes reflexões teóricas entre as Ciências Sociais. Em uma escala mais ampla, o que tem se discutido é a própria laicidade brasileira e suas características.

Um dos nomes de grande destaque na composição do governo de Jair Bolsonaro é o de Damares Alves, responsável pelo Ministério da Mulher, da Família e dos Direitos Humanos. Figura controversa, Damares é originalmente uma pastora evangélica, ativista pró-vida, que possui vínculos de longa data com membros da Frente Parlamentar Evangélica (FPE)- chegando inclusive a ser assessora parlamentar (2003-2019) ${ }^{1}$ do ex-senador Magno Malta, um dos cabos eleitorais mais proeminentes de Jair Bolsonaro e membro ativo da FPE. Em 2018, Damares Alves foi anunciada como ministra do governo Bolsonaro para o que, sob sua gestão, deixaria de chamar-se somente Ministério dos Direitos Humanos e incorporaria ao antigo nome os termos "Família" e "Mulher". Damares Alves apresenta-se como expoente de uma Direita Cristã que se vislumbra no país e que tem uma atuação política pautada por valores morais religiosos e é marcadamente reativa, pois busca confrontar-se com grupos políticos e sociais mais progressistas.

Esses movimentos de reconfiguração ideológica possibilitados pela eleição de Jair Bolsonaro e consolidados com a posse de Damares Alves, justamente em um ministério referente a temas sensíveis para grupos religiosos e progressistas, têm apresentado consequências que ultrapassam também as fronteiras nacionais. No âmbito do Conselho de Direitos Humanos da Organização das Nações Unidas (ONU), por exemplo, o Brasil ocupa assento que lhe permite participar das discussões que permeiam os consensos internacionais sobre o tema dos direitos humanos e vem apresentando uma substancial inflexão no conteúdo de seus posicionamentos a partir da liderança de Damares e do governo Bolsonaro. Dentro deste contexto, o posicionamento brasileiro nas discussões sobre Direitos Humanos

1 Para saber mais: “Como Damares Alves saiu de ministra 'periférica' a figura central do bolsonarismo”- https://www.bbc.com/portuguese/brasil-53980530. Último acesso em 10/2020. 
da ONU apresenta-se como um caso simbólico de temas que são objeto central de disputa entre atores religiosos e seculares. Torna-se relevante questionar de que maneira a filiação religiosa de Damares Alves e a própria relevância da religião na base política do governo Bolsonaro influenciam a forma como o Brasil tem se apresentado em relação aos direitos humanos.

É a partir deste panorama, levando em consideração a trajetória política e a ideologia declarada de Damares Alves, que o presente texto se insere. Problematiza-se aqui como os valores religiosos da ministra se relacionam com os constrangimentos de uma esfera social pautada por regras seculares e laicas. É possível, nesta reflexão, pensar a relação entre a religião e esfera pública, bem como a forma que as diferentes esferas se adequam e como os atores recorrem, ou não, às regras e discursos que tornam possível a defesa de seus valores. A questão que permeia este estudo é: de que maneira os valores religiosos da ministra influenciam a atuação de seu ministério nas pautas internacionais relativas aos direitos humanos? Para isso, faz-se uso da análise documental dos discursos da ministra perante o Conselho de Direitos Humanos e os múltiplos painéis do órgão nos quais ela se fez presente. Os dados para esta análise foram obtidos junto ao Ministério da Mulher, da Família e dos Direitos Humanos por meio de processo movido com base na Lei de Acesso à Informação no mês de julho de 2020. Foram obtidos oito discursos da ministra, referentes às oito ocasiões em que o Ministério foi por ela representado junto à $\mathrm{ONU}$, que conformam o corpus da análise documental e embasam metodologicamente esta pesquisa.

\section{A LAICIDADE BRASILEIRA, 0 FENÔMENO POLÍTICO EVANGÉLICO E A CONJUNTURA CONTEMPORÂNEA DO BRASIL: DAMARES ALVES E A DIREITA CRISTÃ BRASILEIRA}

Para que se compreenda a conjuntura que intermedia a relação entre atores políticos com motivação religiosa e as instituições políticas contemporâneas, dois conceitos são fundamentais: o conceito de secularização, que teoriza processos por meio dos quais as sociedades adentram em ordens sociais seculares em que a religião perde influência e assume outro lugar nestas sociedades; e o conceito de laicidade, relativo a uma configuração de Estado típica - mas não fundamental de sociedades seculares.

A análise de Max Weber funda o paradigma da secularização ao descrever um processo de emancipação das diferentes esferas sociais da influência religiosa. Cada vez mais pautadas pelo domínio da técnica e, em certo aspecto, por uma visão desencantada do mundo, domínios outrora regidos pela lógica da religião passaram a ser pautados por regras próprias de funcionamento. Esferas sociais 
como Direito, Economia, Estética, dentre outras, se racionalizaram, passando a constituir regras próprias para o seu funcionamento, desvinculadas ou não mais determinadas pela religião. Com isso, as sociedades viram a religião ser relegada a um novo papel e o Ocidente vivenciou a construção, por exemplo, de uma comunidade política pautada sobre suas próprias regras racionais, discutíveis e, em consequência, revisáveis (WEBER, 1982).

Antônio Pierucci (1998) pontua que a descrição do processo de secularização por Max Weber não sustenta, ao contrário do que frequentemente argumentado, uma "tese" que prevê e defende que a emancipação das esferas deva acontecer em todo o mundo. Nesta seara, o debate sociológico tem evidenciado as particularidades na maneira como diferentes sociedades se relacionam com a religião e como vivenciam - ou não - seus processos históricos de secularização. No caso de algumas sociedades europeias, a secularização significou a retração da religião para a esfera privada e, inclusive, o declínio de suas práticas. Contudo, conforme a compreensão se expandia e a realidade dos objetos analisados se tornava mais complexa, observou-se que, para além de uma concepção eurocêntrica de secularização, o processo ao redor do mundo não era linear. O que autores como José Casanova (1994) observam é que, na prática, o processo de secularização apresenta-se de maneira muito plural em diferentes sociedades. Nos Estados Unidos e em algumas sociedades pós-coloniais, a secularização não é sinônimo nem da diminuição da prática religiosa ou tampouco da privatização da religião. Ainda que as esferas sociais tenham de fato se desfeito da legitimação religiosa, este processo não resultou na retirada dos atores religiosos da esfera pública. Mais do que isso: os tensionamentos entre público e privado marcados pelo projeto político secularista inspiraram inclusive o ressurgimento de estratégias de inserção religiosa por meio da atuação no debate público em diversos países. É neste contexto que se insere o que se costuma chamar de "fundamentalismo" religioso. Desde a década de 1980 a religião voltou paulatinamente a ser ator importante no debate público sobre diversos temas (CASANOva, 1994).

Charles Taylor (2010) contribui com este debate ao propor uma análise da ordem secular estabelecida no Ocidente após a secularização. Segundo ele, as sociedades ocidentais contemporâneas apresentam, em grande medida, uma ordem de separação entre Estado e Igreja em que há certa liberdade na maneira pela qual os indivíduos podem se conectar com a religião. A sociedade seria a união de crentes e não crentes, que estabelecem relações no âmbito de diferentes esferas sociais. Estas esferas, por sua vez, estariam pautadas por uma autonomia adquirida a partir do desenvolvimento de racionalidades próprias, distintas da racionalidade religiosa 
que outrora determinava a lógica social. Isto implica figurar que, na contemporaneidade, atores religiosos estão presentes na sociedade em constante relação com atores seculares. Porém, o que diferenciaria esta ordem de uma ordem não secular seria o fato de que estas relações são, agora, intermediadas por lógicas próprias de esferas autônomas - tais como o Estado laico e suas regras procedimentais que relegam a atores políticos religiosos os mesmos constrangimentos e padrões de comportamento que atores políticos seculares.

O que Taylor propõe, para além destas constatações sobre a ordem secular instituída, é uma análise das condições sob as quais a crença religiosa é estabelecida. O que marca a ordem secular é o fato de que a crença religiosa é apenas uma opção dentre muitas para que os indivíduos alcancem um certo sentimento de completude diante da vida cotidiana. Lísias Negrão (2019) esboça um panorama a respeito da maneira por meio da qual o mercado religioso brasileiro foi instituído. Esta trajetória histórica permite uma melhor compreensão do que seriam as condições para a crença e para a secularidade no Brasil. Em diversos aspectos o país incorporou por meio de seu histórico colonial certas práticas típicas do Ocidente de maneira geral. Ao mesmo tempo, dinâmicas históricas conferiram ao mercado religioso brasileiro particularidades que contextualizam, hoje, a inserção de atores como a Direita Cristã na política brasileira e a própria laicidade do Estado brasileiro na Nova República. Negrão comenta que a formação da sociedade brasileira esteve pautada pela colonização dos católicos portugueses, "seus santos e demônios" em uma manifestação "rústica” de um catolicismo popular, praticado pelos aldeões portugueses que aqui chegaram (NEGRão, 2019, p. 33-34) A este catolicismo uniram-se as religiões afro-brasileiras e indígenas fundamentando um cenário de sincretismo e uma mentalidade religiosa híbrida, densamente mágica e encantada. Mais recentemente, em meados do século XX, surgiram no Brasil as igrejas pentecostais - desde a redemocratização institucionalmente inseridas na política de modo a catalisar sua influência na sociedade brasileira. Hoje, ainda que majoritária, a religião católica conta com fiéis formais despossuídos de um habitus religioso, grande parte frequentadores de outros grupos e adotando crenças e práticas não católicas e mágicas.

É em plena época da consolidação do Estado republicano modernizante e do surto de urbanização e industrialização a partir dos anos de 1930 que os grupos pentecostais iniciam seu percurso para se tornar religiões de massa, rivalizando com o catolicismo popular. Além deles, várias modalidades de cultos afro-brasileiros, tais como umbanda, candomblé, batuque e outros, fixaram-se sobretu- 
do no cenário urbano, onde adquiriram uma importância cultural maior que o número de seus adeptos faria supor. Religiões mágicas, encantadas, portanto. Juntas compuseram todas elas um campo religioso amplo e popular, no Brasil do século XX urbano e rural (NEgRão, 2019, p. 34).

O cenário brasileiro é, portanto, o de uma sociedade que não passou pelo processo de desencantamento aos moldes da Europa protestante. Assim sendo, o estabelecimento de uma ordem secular se deu a partir de um processo político extrarreligioso, introduzido por parte de atores como o próprio Estado. Diferentemente de um processo de racionalização originado do desencantamento, a secularização brasileira se deu por meio de um processo em que se estabeleceu, por exemplo, a "massificação dos rudimentos da racionalidade" (tais como a leitura, escrita, matemática elementar, procedimentos do conhecimento científico) e com a crescente universalização do sistema educacional de ensino básico. Assim, "o Estado e seus aliados privados" tais como grupos de produtores de bens e serviços e os mecanismos de comunicação de massa, em esforço conjunto, obtiveram "êxito em construir uma nação secularizada, de economia fundada na racionalidade instrumental capitalista" (Negrão, 2019, p. 35). De fato, a separação entre o estabelecimento da laicidade e o processo macrossocial de secularização é, em diversas sociedades, um fato marcante. Não à toa que, autores como Jean Beauberot (2011; 2013) diferenciam o que entendem ser um processo de emancipação das esferas sociais e autonomização de suas lógicas em detrimento da lógica religiosa e um processo político originado no Estado e em seus principais atores com o sentido de estabelecer uma lógica laica, em que o Estado não prioriza nenhuma religião em detrimento de outra e tampouco se permite determinar por elas. Estes processos são múltiplos e não necessariamente dependentes - e, como visto, a existência de políticos com motivação religiosa não necessariamente diverge da laicidade do Estado, tendo em vista sua subsunção à racionalidade própria de uma esfera secular como a política.

No caso brasileiro, portanto, evidencia-se uma lógica em que a religião está amplamente presente na sociedade, tanto em nível individual quanto no âmbito da esfera pública. Paralelamente, o Estado brasileiro é, principalmente com a Constituição de 1988, laico. Ainda que não adote explicitamente tal denominação (tendo em vista que nenhum dos artigos constitucionais traga esta previsão), seus princípios formais são os do estabelecimento de uma república democrática, que garanta a liberdade de crença, a autonomia do Estado perante a religião e da religião perante a influência do Estado e veda, por exemplo, a discriminação religiosa. 
Para além da formalidade, a existência historicamente legitimada das religiões na esfera pública e, principalmente, na esfera política, tensiona a compreensão a respeito deste caráter laico do Brasil. À medida em que se questiona se a presença das religiões na esfera política não afeta a independência do Estado perante a religião, abre-se margem para compreensões como as de Roberto Blancarte (2011), para quem as sociedades latino-americanas desenvolveram modelos de pluri-confessionalidade. Por meio desta configuração, mais de uma religião influencia as dinâmicas políticas do Estado - tais como os católicos e os pentecostais, por exemplo, que organizados politicamente passam a barganhar seus interesses perante o Estado em detrimento de religiões menos mobilizadas politicamente, como as religiões espírita.

A ascensão de políticos evangélicos vem recebendo atenção por parte de estudiosos, políticos e sociedade. A partir disso, cabe pontuar um terceiro conceito central para esta análise: o de Direita Cristã, relevante para a compreensão da atuação política de evangélicos e para melhor analisar a ascensão de figuras como a ministra Damares. Com uma entrada relativamente tímida na Constituinte, buscando defender seus interesses frente à identificação do perigo de aumento de poder da Igreja Católica na nova Constituição, os evangélicos ascenderam e se profissionalizaram como agentes políticos. A entrada de evangélicos para a política na década de 1980 não foi um projeto político definido, porém, uma atitude reativa e defensiva. Como explica Burity (2020), “os evangélicos não 'ingressaram na política' porque lhes faltava algo ou porque tinham um projeto pronto para levar a cabo. Entraram porque algo ameaçava sua integridade e 'razão de ser" (BurITy, 2020, p. 13)². Constituindo a Frente Parlamentar Evangélica, formada por parlamentares de diferentes agremiações religiosas e partidos políticos, a atuação desses parlamentares religiosos consolidou-se como ator político de relevância no debate público brasileiro.

Chamando a atenção por sua defesa acirrada de pautas morais, sua atuação política não é marcada somente por interesses religiosos. Pragmáticos e numerosos, esses parlamentares souberam se adaptar ao jogo político do Congresso Nacional, compuseram a base de sustentação dos governos de Lula da Silva, Dilma Rousseff e Michel Temer, avançaram pautas econômicas e fiscais de interesse das Igrejas, barraram o avanço de projetos, ocuparam ministérios e, inclusive, envolveram-se

2 No original: "los evangélicos no 'igresaron a la política' porque lesfaltaba algo o porque tenían um proyeto listo para llevar a cabo. Entraron porque algo amenazabasuintegridad y 'razón de ser". 
em escândalos de corrupção ${ }^{3}$. Não admira, portanto, a diversidade de pesquisas desenvolvidas sobre sua ascendência no cenário brasileiro: seja sobre o aumento de fiéis evangélicos na sociedade, acompanhado de uma diminuição no número de católicos, seja tentando compreender a forma como as diferentes Igrejas se organizam em campanhas eleitorais, ou, ainda, sobre a forma como se dão suas votações no Congresso e se sua atuação parlamentar está condicionada às diretrizes de seus respectivos partidos políticos ou de suas respectivas Igrejas, e, além disso, levantamentos e análises sobre os diferentes projetos de leis em que a atuação do grupo foi substancial (Freston, 1993; Mariano; Pierucci, 1992; Maia, 2012; Novaes, 2001; Pierucci; Prandi, 1995; Trevisan, 2013).

Joanildo Burity (2020) lembra que os evangélicos têm sido bastante pragmáticos em suas escolhas perante os candidatos à Presidência da República: assim como costumam ser contundentes críticos do comunismo e da esquerda, apoiaram Lula e Dilma, integrando a base de apoio no Congresso de ambos os governos e fazendo negociações para conseguir emplacar suas demandas ou travar o debate sobre temas que lhes são caros, como o aborto. Utilizaram seu apoio como moeda de troca, demonstrando habilidade para a utilização das regras do jogo político. Nas últimas eleições presidenciais, por exemplo, o apoio ao, então, candidato Jair Bolsonaro não veio em um primeiro momento, mas sim em um movimento que aconteceu conforme a campanha foi avançando e a vitória do candidato tomou forma. Somente uma semana antes do primeiro turno das eleições, explica o autor, o líder da Igreja Universal do Reino de Deus, Edir Macedo, declarou apoio a Bolsonaro (BURITY, 2020, p. 12). No entanto, autores como Ricardo Mariano e André Gerardi (2019) assinalam o apoio dos evangélicos a Bolsonaro por uma confluência das posições políticas:

Líderes evangélicos apoiaram Bolsonaro, acima de tudo, por considerá-lo representante legítimo de seus valores e capaz de derrotar o inimigo petista e os perigos que lhe atribuíram: implantar o comunismo, perseguir os cristãos, abolir o direito dos pais de educar os filhos, reorientar a sexualidade das crianças, destruir famílias (GERARdi; MARIANo, 2019, p. 69).

A conjuntura política do país pós-2014, com o impeachment da presidenta Dilma Rousseff e os escândalos de corrupção revelados pela Operação

3 Para saber mais: “58\% da propina foi para evangélicos, diz CPI dos Sanguessugas” https://www1. folha.uol.com.br/folha/brasil/ult96u81306.shtml. Último acesso em outubro de 2020. 
Lava Jato ${ }^{4}$, acabaram por marcar o aparecimento de um novo tipo de atuação política no país, momento em que grupos e movimentos sociais autoproclamados de direita ${ }^{5}$ ganharam mais relevância no cenário político. Além de atores do campo evangélico que forçavam o debate público principalmente no campo moral, passou-se a observar outros atores políticos que buscavam construir um campo de antagonismo com os governos petistas e com a visão de mundo progressista. Os debates passaram a girar em torno de temas como corrupção, comunismo, socialismo, ditadura, feminismo, aborto, esquerda/direita, etc. Todo este cenário social acabou por levar a uma campanha eleitoral marcadamente polarizada: segundo a análise de Geofrey Pleyers (2021), esta polarização da sociedade brasileira em 2018 teria se refletido também nas distintas denominações evangélicas, particularmente, entre os neopentecostais. Para ele, "a batalha que está se dando no Brasil, como em várias regiões do mundo, não opõe os católicos de um lado e os evangélicos de outro, senão correntes conservadoras e progressistas que atravessam distintas confissões religiosas" (Pleyers, 2021, p. 67). Segundo o autor, esta polarização, aliada ao anti-esquerdismo, teria contribuído para a consolidação de uma Direita Cristã no Brasil, uma vez que estas posições políticas de repúdio à esquerda nortearam a atuação de políticos evangélicos que passaram cada vez mais a auto identificarem-se como conservadores. Como reflexo deste cenário político social, em 2018, Jair Bolsonaro elegeu-se como Presidente da República utilizando o slogan "Brasil acima de tudo, Deus acima de todos". Bolsonaro se autoproclamava como um conservador, cristão e de direita, e sua campanha eleitoral foi fortemente marcada por um discurso anti-esquerda, anti-petista e anti-comunista.

A atuação política dos evangélicos é aqui conectada e pensada junto à categoria de direita. De acordo com o proposto neste trabalho, unindo os dois espectros tem-se a expressão da Direita Cristã no Brasil. Ou seja, o segmento político dentro da direita que atua pautado por valores morais cristãos. Por tratar-se de um segmento do lado à direita da política, não constitui todo o campo da direita no Brasil, nem mesmo da atuação contemporânea da direita que se vem observando pós-2014. Neste sentido, é importante definir o que se entende por direita neste trabalho: para Norberto Bobbio (1995), esquerda e direita não indicam apenas a existência de ideologias diversas, mas, acima disso, "indicam programas contrapostos com relação a diversos problemas cuja solução pertence habitualmente à ação política, contrastes não só de ideias, mas também de interesses e de valorações

4 Para mais informações sobre a Operação do Ministério Público: http://www.mpf.mp.br/grandes-casos/lava-jato/entenda-o-caso. Último acesso em 10/2020.

5 Entre eles movimentos sociais como "Vem pra Rua", "Nas Ruas", "Movimento Brasil Livre". 
[valutazione] a respeito da direção a ser seguida pela sociedade” (BoвBIo, 1995, p. 33). O autor utiliza o posicionamento em relação à igualdade como critério de demarcação para esquerda e direita. A esquerda tem a aspiração à igualdade como uma das razões fundamentais, enquanto isso, segundo Bobbio, a direita é inigualitária; "o igualitário parte da convicção de que a maior parte das desigualdades que o indignam, e que gostaria de fazer desaparecer, são sociais e, enquanto tal, elimináveis; o inigualitário, ao contrário, parte da convicção oposta, de que as desigualdades são naturais e, enquanto tal, inelimináveis” (Воввіо, 1995, p. 105). O autor ainda pontua que a defesa da desigualdade, ou a aceitação desta, feita pela direita não está vinculada à "más intenções", outrossim, um reconhecimento de que as desigualdades não são apenas inelimináveis como são também úteis, por gerarem a incessante luta pelo melhoramento da sociedade (BoвBIo, 1995).

Além da referência à igualdade, a tradição também ocupa um lugar na dicotomia esquerda e direita. Ao passo que a direita representaria a defesa do passado, da tradição e da herança; a esquerda representaria a libertação do homem do poder político e opressivo, a emancipação (Bоввıо, 1995). É possível, também, encaixar a díade em uma metáfora temporal, em que: a esquerda estaria vinculada à inovação e progresso, enquanto a direita vincular-se-ia à conservação e tradição. Diferenciando, assim, "os que se deixam guiar pelo sol do futuro dos que procedem guiados pela inextinguível luz que vem do passado" (Воввіо, 1995, p. 69). Algumas características são perceptíveis de forma mais clara, mesmo que não se busque esgotar a complexidade da realidade, ao que se entende por direita e esquerda. Portanto, de forma a tentar dar clareza a análise que será feita e como exercício teórico-metodológico, definir-se-á, neste trabalho, esquerda como grupo político que atua pautado pela busca de igualdade entre indivíduos e com primazia pelo coletivo; e direita como grupo político que atua priorizando a liberdade e que, portanto, preterindo o coletivo em prol do indivíduo. Além disso, as categorias de progresso e tradição também serão usadas como demarcadores de esquerda e direita, situando-se, progresso à esquerda e tradição à direita.

Kimberly Conger (2019) ao pensar a Direita Cristã americana pontua que esta tem como seu núcleo o povo evangélico protestante, que acaba se organizando politicamente como reação às transformações culturais que a sociedade americana vislumbrou a partir das décadas de 1960 e 1970. A autora define, então, a Direita Cristã como um movimento social moderno que atua na esfera pública com base em valores socialmente conservadores (no sentido de conservar o corpo social e seus valores constituintes). Ainda, destaca Conger, constitui-se de uma rede solta de organizações que possui compromisso com o protestantismo e pautas morais 
cristãs como: oposição ao aborto; oposição ao casamento de pessoas do mesmo sexo; apoio à educação baseada na fé, dentro e fora das escolas e algumas outras questões que sustentam esses compromissos centrais do movimento (CONGER, 2019).

A Direita Cristã Brasileira será compreendida nesta pesquisa como um dos braços da direita do país, primordialmente representada pela atuação política e social de evangélicos como Damares Alves, que tem como corpo constituinte de suas pautas políticas valores morais cristãos e a busca pela difusão destes valores no campo cultural da sociedade, ao mesmo tempo em que busca barrar o avanço de transformações culturais que possam vir a ferir seu quadro de compreensão do mundo. A ação política dos evangélicos, portanto, abre caminho para a consolidação de uma Direita Cristã no Brasil contemporâneo.

\section{DAMARES ALVES: MINISTRA "TERRIVELMENTE EVANGÉLICA"}

É no contexto político explicado na sessão anterior que ganha proeminência a figura de Damares Alves. Entrelaçada pela ascensão do bolsonarismo, Damares acaba sendo nomeada para o Ministério trazendo em si a confluência de diversos elementos que sustentam ideologicamente o governo de Jair Bolsonaro. Sua trajetória de vida explica esta relação por si só: Damares tem intenso histórico de ativismo ligado a temas como aborto, povos indígenas, mulheres e crianças. Foi fundadora e coordenadora de diversas ONGS, entre elas: Instituto Flores de Aço; Movimento Atini - Voz pela Vida; Movimento Nacional pela Cidadania Brasil Sem Aborto; Movimento Brasil Sem Dor. O ativismo pró-vida ou anti-aborto é um dos mais fortes em sua trajetória, além de participar de "Marchas pela Vida", Damares, por sua relevância para o movimento, discursava em carros de som nos eventos defendendo que a vida fosse respeitada a partir do nascituro ${ }^{6}$.

Além disso, como secretária geral do Movimento Brasil Sem Aborto, ela assinou uma nota de incentivo 7 para que os "defensores da vida" fizessem pressão em parlamentares pela aprovação do projeto de lei PL 478/2007 ${ }^{8}$, que ficou conhecido como Estatuto do Nascituro. O projeto de lei (PL) "dispõe sobre a proteção integral ao nascituro", compreendendo que "nascituro é o ser humano concebido, mas ainda não nascido", e, por fim, designa que “o nascituro adquire personalidade jurídica

6 Para saber mais: “Flores na Marcha pela vida contra o aborto!"http://institutofloresdeaco.blogspot.com/2014/11/flores-na-marcha-pela-vida-contra-o.html?q=damares. Último acesso em 10/2020.

7 Para saber mais: “Comunicado sobre o PL 478/2007 (Estatuto do Nascituro)" https://brasilsemaborto.org/projetos-de-lei/comunicado-sobre-o-pl-4782007-estatuto-do-nascituro/. Último acesso em 10/2020.

8 Para saber mais: "Ficha de tramitação: Projeto de Lei PL 478/2007". https://www.camara.leg. $\mathrm{br} /$ proposicoesWeb/fichadetramitacao?idProposicao=345103. Último acesso em 10/2020. 
ao nascer com vida, mas sua natureza humana é reconhecida desde a concepção, conferindo-lhe proteção jurídica através deste estatuto e da lei civil e penal.” Ao fim e ao cabo, o PL buscava reconhecer direitos jurídicos e, portanto, reconhecer a vida do feto a partir da concepção, buscando inviabilizar ao máximo o aborto, inclusive trazendo tensões para os casos já reconhecidos pela lei brasileira (estupro, risco à mulher e feto anencefálico).

Um dos pontos centrais do Ministério a partir do comando de Damares Alves foi a inclusão do termo Família em seu nome, por meio do qual o governo buscou sinalizar a importância que daria para esta instituição de ordem privada, mesmo que de forma discursiva ou simbólica. Para cuidar deste tema, o Ministério instituiu uma Secretaria Nacional da Família que, segundo seu o site oficial ${ }^{9}$, tem como competências:

Assistir o Ministro de Estado nas questões relativas à formação, fortalecimento e promoção da família; formular políticas e diretrizes para a articulação dos temas, das ações governamentais e das medidas referentes à promoção e defesa da família; coordenar e propor ações transversais no que se refere à formação, fortalecimento e promoção da família; articular ações intersetoriais, interinstitucionais, interfederativas e internacionais para fortalecimento da família; promover a inserção de uma perspectiva de família em todas as áreas de atuação do governo; gerir convênios, termos, acordos e outros instrumentos congêneres relativos à família; coordenar e articular ações com órgãos governamentais e organizações da sociedade civil, bem como com outras secretarias do Ministério para suporte à formação e desenvolvimento da família (MMFDH, 2020).

Além da secretaria especial, alguns programas foram desenvolvidos pensando na atuação do Ministério junto às famílias: Programa Município Amigo da Família (PMAF); Observatório Nacional da Família (ONF); Famílias Fortes; Programa Reconecte; Projeto Acolha a vida. Os projetos vão desde temas como suicídio, adoção, pesquisas para políticas públicas pensadas para famílias, até a promoção "[d]o bem-estar dos membros da família, fortalecendo os processos de proteção e construção de resiliência familiar e reduzindo os riscos relacionados a comportamentos problemáticos" (MMFDH, 2020) ${ }^{10}$.

9 Para saber mais: "Ministério da Mulher, da Família e dos Direitos Humanos" https://www.gov. $\mathrm{br} / \mathrm{mdh} / \mathrm{pt}$-br/acesso-a-informacao/competencias. Último acesso em 10/2020.

10 Para saber mais: "Ministério da Mulher, da Família e dos Direitos Humanos" https://www.gov. $\mathrm{br} / \mathrm{mdh} / \mathrm{pt}$-br/navegue-por-temas/familia/familias-fortes. Último acesso em 10/2020. 
É a partir da defesa destes valores, comuns à Direita Cristã e à base ideológica do governo de Jair Bolsonaro, que a atuação da ministra vem sendo pautada. Por meio da análise de seus posicionamentos em esferas como o Conselho de Direitos Humanos da ONU, evidencia-se como grande parte destes valores fundamentam o posicionamento brasileiro no órgão. Ao mesmo tempo, evidencia-se que a narrativa defendida ao longo da trajetória política da ministra encontra constrangimentos cruciais para sua manutenção em uma esfera laica como a ONU e, principalmente, enquanto representação de um Estado laico como o brasileiro.

\section{ENTRE CONSTRANGIMENTO E AUTOPROTEÇÃO: OS DILEMAS DA LAICIDADE NOS DISCURSOS DE DAMARES ALVES NO CONSELHO DE DIREITOS HUMANOS DA ONU}

Nesta seção são analisados oito discursos proferidos por Damares Alves na Comissão de Direitos Humanos da ONU à frente do Ministério da Mulher, Família e Direitos Humanos, desde sua tomada de posse em 2019. Como explicado no início deste artigo, todos os discursos foram disponibilizados a esta pesquisa via Lei de Acesso à Informação - LAI ${ }^{11}$, e referem-se aos seguintes eventos: $40^{\mathrm{a}}$ sessão do Conselho de Direitos Humanos da Organização das Nações Unidas; $43^{\text {a }}$ sessão do Conselho de Direitos Humanos da Organização das Nações Unidas; Convenção sobre os Direitos da Criança - 30 anos; Painel de alto nível sobre o $25^{\circ}$ aniversário da Conferência de Pequim; Painel de Alto Nível em comemoração aos 25 anos da Quarta Conferência Mundial sobre a Mulher - Declaração em nome da Comunidade de Países de Língua Portuguesa (CPLP); Abertura da Exposição Fotográfica "Rare Exhibit", em comemoração ao dia das pessoas com doenças raras; Evento paralelo sobre violações de direitos humanos na Venezuela e "Liberdade de Religião ou crença: entendendo o passado para proteger as vítimas de hoje” - Evento paralelo à $43^{\mathrm{a}}$ sessão do Conselho de Direitos Humanos.

De maneira geral, os discursos da ministra são demarcados por alguns dos conflitos políticos do momento, além de buscar apresentar as posições do novo governo à comunidade internacional (principalmente após a repercussão de posicionamentos do então eleito Presidente, Jair Bolsonaro, e os direitos humanos - como em sua defesa de um notório torturador do período ditatorial no Brasil ${ }^{12}$ ). Já

11 Para saber mais: "Lei $\mathrm{n}^{0}$ 12.527, de 18 de novembro de 2011". http://www.planalto.gov.br/ccivil_03/_ato2011-2014/2011/lei/l12527.htm. Último acesso em 10/2020.

12 Para saber mais: "Bolsonaro diz no Conselho de Ética que Coronel Ustra é herói brasileiro". https://www.youtube.com/watch?v=xiAZn7bUC8A; http://g1.globo.com/politica/noticia/2016/11/ bolsonaro-diz-no-conselho-de-etica-que-coronel-ustra-e-heroi-brasileiro.html; https://www. infomoney.com.br/politica/conheca-o-livro-de-cabeceira-de-jair-bolsonaro-a-verdade-sufocada/. Último acesso em outubro de 2020. 
em seu primeiro discurso, o Brasil busca contrapor-se às críticas e comprometer-se com a defesa dos direitos humanos e da democracia. Além disso, este primeiro discurso, realizado no âmbito do segmento de alto nível da $40^{\mathrm{a}}$ sessão do Conselho de Direitos Humanos da ONU, perpassa todos os grupos socialmente minoritários mulheres, LGBT, negros, crianças vulneráveis - e assume compromisso de garantir os direitos humanos destes grupos, assegurando que o governo buscará fortalecer as políticas públicas que garantam melhores condições para tais minorias.

Neste momento, foram apresentadas algumas diretrizes que viriam a pautar a política do Ministério sob o comando de Damares Alves e que foram retomadas nos discursos posteriores. Destacam-se a defesa do direito à vida "desde a concepção", os esforços no enfrentamento da discriminação e da violência contra as mulheres, "sobretudo o feminicídio e o assédio sexual", a defesa do direito das crianças (reiterado em diversos discursos e, principalmente, no painel próprio sobre o tema na $43^{\mathrm{a}}$ sessão do Conselho), o "fortalecimento dos vínculos familiares", a intensificação das medidas de proteção de pessoas com deficiência e pessoas idosas e, como mencionado, o combate ao racismo e a discriminação contra pessoas LGBT e uma ênfase especial na proteção dos direitos dos povos indígenas - pauta diretamente ligada à trajetória política e pessoal da ministra, que apresenta-se como mãe de uma menina indígena através de um polêmico processo de adoção ${ }^{13}$. O Programa de Proteção aos Defensores de Direitos Humanos, o programa de HIV/Aids e o programa nacional de alfabetização também foram mencionados.

Também desde seu primeiro discurso, Damares busca ressaltar que o Brasil é um país laico, mas não laicista, ou seja, que preserva a existência de todas as formas de crença e não busca a exclusão delas da esfera pública. Essa posição de, por um lado, reconhecer e ressaltar a laicidade do Estado e, por outro, de sublinhar o espaço da religião na sociedade (inclusive no governo) repete uma dinâmica do próprio presidente Bolsonaro, que busca sempre salientar a laicidade e, ao mesmo tempo, sua posição cristã, como em tal declaração: "Agora, sou um presidente que diz que o Estado é laico, mas ele [o presidente] é cristão"14.

13 Para saber mais: "Damares apresenta a filha adotiva e diz que não sequestrou ninguém”. https://epoca.globo.com/damares-apresenta-filha-adotiva-diz-que-nao-sequestrou-ninguem-23682848. Último acesso em outubro de 2020.

14 Para saber mais: "Estado é laico, mas ele é cristão", diz Bolsonaro na Marcha para Jesus https:// exame.com/brasil/o-estado-e-laico-mas-ele-e-cristao-diz-bolsonaro-na-marcha-para-jesus/; https://noticias.uol.com.br/politica/ultimas-noticias/2020/02/o8/presidente-em-evento-evangelico-estado-e-laico-mas-bolsonaro-e-cristao.htm; https://valor.globo.com/politica/ noticia/2020/02/15/o-brasil-e-laico-mas-o-presidente-e-cristao-diz-bolsonaro.ghtml; https:// www.diariodepernambuco.com.br/noticia/politica/2020/o9/o-estado-e-laico-mas-nosso-governo-e-cristao-diz-bolsonaro-no-twit.html. Último acesso em outubro de 2020. 
Outro fator político de relevo que acaba surgindo nos posicionamentos da ministra é a crítica ao governo de Nicolás Maduro na Venezuela. Já com posição demarcada devido aos embates da campanha eleitoral ${ }^{15}$, o governo de Jair Bolsonaro busca ser um crítico contumaz da ditadura venezuelana, como forma de se contrapor à esquerda e ao socialismo. Além disso, logo após a posse de Bolsonaro, em janeiro de 2019, a crise venezuelana se acentua e Juan Guaidó, líder da oposição e presidente da Assembleia Nacional da Venezuela, se autodeclara presidente interino do país ${ }^{16}$. O Brasil assume a posição de reconhecer sua legitimidade como presidente. Tais questões se refletem nos discursos da ministra, por meio dos efeitos humanitários da crise, como a violação dos direitos humanos dos opositores políticos de Maduro e dos venezuelanos que têm abandonado o país pela miséria eminente. O Brasil tem sido um dos principais atores envolvidos na acolhida aos refugiados venezuelanos ${ }^{17}$. Em seu discurso na $43^{\mathrm{a}}$ sessão, ela menciona o trabalho da Missão de Verificação de Fatos, que investiga abusos de poder do Estado comandado por Maduro, a marca de 1 milhão de atendimentos emergenciais a venezuelanos na fronteira e a facilitação do reconhecimento do status de refugiado para estas pessoas. Em um evento paralelo dedicado ao tema, ela reiterou a crítica ao regime venezuelano e defendeu sua ilegitimidade, exaltando o trabalho da Operação Acolhida empreendida pelo governo brasileiro.

O que seus posicionamentos evidenciam de maneira geral é uma tentativa de não se opor aos consensos estabelecidos no âmbito da ONU e de sustentar a posição que o país ocupa no Conselho. A ministra chega a afirmar isto de maneira explícita em seu primeiro discurso ao dizer que o Brasil continuará plenamente engajado com o sistema internacional de direitos humanos. Neste momento, ela convida as representações presentes a apoiarem a candidatura do Brasil ao Conselho nas eleições que aconteceriam em outubro (nas quais o país viria ser reeleito). Além disso, é feito também um convite para que os relatores especiais do Conselho fossem ao país, assim como é adotado o compromisso de manter atualizados os relatórios pendentes do Brasil perante a instituição. Em seu segundo discurso, realizado

15 Para saber mais: "Venezuela: Bolsonaro fala sobre "ditadura de Maduro" e rejeita intervenção" https://www1.folha.uol.com.br/poder/2018/10/no-radio-bolsonaro-associa-pt-a-venezuela-e-haddad-critica-violencia.shtmlhttps://noticias.uol.com.br/politica/eleicoes/2018/noticias/2018/o9/20/campanha-de-bolsonaro-associa-adversarios-a-maduro-para-atrair-votos.htm ; https://exame.com/mundo/venezuela-bolsonaro-fala-sobre-ditadura-de-maduro-e-rejeita-intervencao/Último acesso em outubro de 2020.

16 Para saber mais: "Juan Guaidó se declara presidente interino da Venezuela e é reconhecido por Brasil e EUA” https://g1.globo.com/mundo/noticia/2019/o1/23/juan-guaido-presta-juramento-como-presidente-interino-da-venezuela.ghtmlÚltimo acesso em outubro de 2020.

17 Para saber mais: "Operação Acolhida”, ver https://www.gov.br/acolhida/historico/. Último acesso em outubro de 2020. 
no âmbito da $43^{\mathrm{a}}$ sessão do Conselho, ela agradece a reeleição do país e lembra o esforço em atualizar os relatórios pendentes do Brasil aos órgãos de tratados. Esses esforços, diz ela, são uma demonstração do engajamento e compromisso do governo Bolsonaro com o sistema internacional de proteção aos direitos humanos.

Esses posicionamentos acontecem em um contexto político de muitas dúvidas a respeito do comprometimento do governo de Bolsonaro no que tange aos direitos humanos. Na institucionalidade do Conselho e das próprias Nações Unidas, a ministra não parece buscar o rompimento com os consensos estabelecidos, pelo contrário: Damares ratifica e sublinha o compromisso do governo Bolsonaro com todos os grupos minoritários, busca destacar ações públicas que viriam a ser tomadas, ou que seriam continuadas, para cada um deles. Assume, inclusive, o compromisso de viabilizar a igualdade entre homens e mulheres e o empoderamento de todas as mulheres, pauta feminista defendida pela $\mathrm{ONU}^{18}$.

O exemplo do apoio às pautas feministas, muitas vezes opostas ao conservadorismo da Direita Cristã, mostra que, ainda que demarque posição em alguns temas como a defesa da vida desde a concepção, por exemplo, a atuação da ministra na ONU se mostra constrangida pelos ordenamentos institucionais, assumindo e reproduzindo as regras do ambiente institucional em que se faz presente enquanto representante pública. Nesse sentido, é possível perceber a atuação do ator político orientada de acordo com as regras e constrangimentos de cada esfera social: enquanto representante de um país na ONU, Damares orienta-se pela esfera em que está inserida - quando altera-se a esfera, como por exemplo, quando atua como pastora ou como ativista, seu comportamento será orientado de acordo com as regras de tais esferas. A esfera social emancipada sob a lógica secular possui um ordenamento de regras formais, ou meramente comportamentais-sociais, que constrangem o ator e provocam sua adequação. Neste contexto, o rompimento com as regras do jogo traria consequências políticas que talvez não fossem rentáveis. Não é de se estranhar, portanto, que os discursos políticos sejam por diversas vezes destoantes da prática, pois estas buscam muito mais conquistar a aceitação de outros atores do que, necessariamente, seguir suas diretrizes ideológicas.

Dessa forma, vislumbram-se alguns tensionamentos em relação a temas que, muito frequentemente, são pauta do discurso político de atores religiosos. Estes elementos demonstram a maneira como a religião é tratada nos discursos de Damares e de como as figuras de agente público e pastora são confrontadas. No

18 Para saber mais: “ONU Mulheres: Princípios de empoderamento das mulheres, novembro de 2017”. http://www.onumulheres.org.br/wp-content/uploads/2016/o4/cartilha_ONU_Mulheres_Nov2017_digital.pdf. Último acesso em outubro de 2020. 
que tange à laicidade do Estado, por exemplo, a ministra ao mesmo tempo em que é constrangida por esta institucionalidade, é também por ela beneficiada. Se por um lado se vê impedida de romper com diversos consensos previamente estabelecidos, por outro, encontra margem para, através da defesa da laicidade, promover o respeito à liberdade religiosa - como visto, por exemplo, através do copatrocínio do país no evento paralelo à $43^{\mathrm{a}}$ sessão do Conselho que visava o debate sobre a liberdade religiosa ou de crença. Como dito em seu primeiro discurso, o Brasil é, segundo ela, um país laico, mas não laicista. Trata-se de um importante posicionamento em uma instância de debate que dialoga com diversas perspectivas políticas e ideológicas que se confrontam diretamente com a religião - tais como alguns grupos feministas ou LGBT, por exemplo. No evento paralelo à $43^{\mathrm{a}}$ sessão do Conselho, Damares afirmou que "a religião e a espiritualidade podem contribuir para a promoção da dignidade e valor inerentes à pessoa, bem como para promover uma cultura de paz e tolerância”.

A questão da liberdade religiosa deslocou-se para uma posição central do posicionamento brasileiro sob a gestão de Damares. Segundo ela, a perseguição religiosa atinge pelo menos um terço da população mundial, caracterizando a temática como uma das principais questões de direitos humanos da atualidade. Ataques pautados pela intolerância religiosa demonstram, como dito por ela ainda no evento paralelo sobre liberdade religiosa e de crença, a necessidade de que os esforços para promoção do direito de liberdade de pensamento, de consciência, de religião e de crença sejam incrementados ${ }^{19}$.

Alguns tópicos sensíveis a atores religiosos, especialmente neopentecostais, estão presentes no discurso de Damares, tais como os direitos da população LGBT e questões relativas ao direito das mulheres. Tanto em seu primeiro discurso quanto nos posteriores, ela reiterou uma postura de combate à violência e a discriminação contra pessoas LGBT por meio da utilização de uma diretoria específica do Ministério para o desenvolvimento de políticas públicas nesse sentido. $\mathrm{Na}$ ocasião da $43^{\mathrm{a}}$ sessão, por exemplo, ela mencionou um programa de capacitação e empregabilidade para a população transexual. Em relação ao direito das mulheres, comprometeu-se com a busca pela equidade entre homens e mulheres, bem como

19 É neste sentido que o Ministério de Damares tem sido peça chave na articulação do Brasil com diversos atores internacionais que buscam a promoção da liberdade religiosa a nível mundial: a ministra participou, por exemplo, do Segundo Encontro Ministerial sobre Liberdade Religiosa em Washington e o Brasil aderiu à Aliança para Promover a Liberdade Religiosa como membro fundador - como dito por ela em um de seus discursos. Para mais sobre isso, ver: https:// br.usembassy.gov/pt/segunda-reuniao-ministerial-historica-para-promover-a-liberdade-religiosa/ e https://www.gazetadopovo.com.br/vida-e-cidadania/principios-da-alianca-pela-liberdade-religiosa/. Último acesso em outubro de 2020. 
o combate à violência contra mulheres e meninas. No Painel de Alto Nível em comemoração aos 25 anos da Quarta Conferência Mundial sobre a Mulher, o Brasil chegou a representar a Comunidade de Países de Língua Portuguesa e defender as políticas da comunidade compromissadas com a promoção dos direitos das mulheres, com a igualdade de gênero, com o fim de toda forma de violência contra mulheres e meninas e o combate ao feminicídio. Na mesma conferência, o Brasil também obteve espaço para pronunciamento individual, por meio do qual Damares defendeu que o tema é central para sua gestão, que tem por objetivo a erradicação da violência e a maior participação política das mulheres - representado pela meta de que todos os municípios tenham pelo menos uma mulher vereadora. A ministra também mencionou a criação da Comissão da Amazônia, que tem como um de seus objetivos proteger a mulher indígena.

Se, por um lado, alguns posicionamentos do Ministério sob a gestão de Damares entram em franco conflito com posicionamentos religiosos hegemônicos da Direita Cristã, algumas pautas têm sido claramente delimitadas em consonância com a crença religiosa. Em relação ao direito à vida, por reiteradas vezes a ministra defendeu a postura de que o país compreendia o exercício do direito desde a concepção - posição central para a Direita Cristã e claramente destoante de grupos que objetivam a legalização da prática do aborto. Além disso, já em seu primeiro discurso o "fortalecimento dos vínculos familiares" foi defendido - a família enquanto instituição social e que recebe substancial importância no pensamento conservador, assim como no religioso.

Também, cabe mencionar que a centralidade de temas dos discursos de Damares Alves analisados está nas seguintes questões: combate à violência contra mulheres e crianças, questão indígena, liberdade religiosa, crise humanitária da Venezuela e manutenção do posto do Brasil perante o Conselho dos Direitos Humanos. Questões como o direito das pessoas LGBT, ainda que mencionadas, receberam menos espaço quando comparadas a outros temas. Pode-se até mesmo pontuar que estas considerações foram bastante descritivas e superficiais, enquanto que questões como as relativas à liberdade religiosa, por exemplo, receberam um posicionamento mais propositivo por parte do Brasil. Percebe-se que, dentre os temas consensuais, alguns acabaram por ser preferidos em função de outros e a variável da religião parece receber influência positiva nesta escolha.

\section{CONCLUSÕES}

A atuação política de evangélicos, institucionalizada por meio da Frente Parlamentar Evangélica, já é tema consolidado entre as pesquisas de Ciências Sociais. 
Compreender de que forma este novo ator político contribui para a reconfiguração dos arranjos entre religião e política, a laicidade brasileira e a secularização da sociedade são objetivos que ocuparam o debate acadêmico nos estudos de Antropologia, Sociologia e Ciência Política das últimas décadas. No entanto, o cenário político brasileiro dos últimos anos, mais especificamente pós-impeachment da presidenta Dilma Rousseff, trouxe novas variáveis para este cenário entre religião e política no Brasil: o avanço de atores políticos declaradamente de direita no país, a diminuição de poder político das esquerdas e a eleição de um presidente assumidamente cristão de direita, apoiado por proeminentes lideranças políticas evangélicas. A FPE alcança, portanto, uma posição com maior probabilidade de influência junto ao poder executivo brasileiro e Damares Alves, no papel de ministra do governo Bolsonaro, reflete esta influência.

Damares é pensada, neste artigo, como uma figura que comporta em sua atuação uma confluência de fatores sociais e políticos das conjunturas nacional e internacional. Pastora, ativista pró-vida, assistente parlamentar da Frente Parlamentar Evangélica, Damares é uma representante da Nova Direita Cristã que vem se consolidando no Brasil. $\mathrm{O}$ trabalho dedicou-se à atuação de Damares enquanto representante do Brasil na Comissão de Direitos Humanos da ONU por meio da análise dos discursos proferidos por ela em alguns dos painéis e conferências em que se fez presente. Buscou-se compreender de que forma a religião exerce influência, ou não, nos posicionamentos de Damares Alves na ONU.

A secularização torna-se um conceito poderoso para tal objetivo, uma vez que nos traz as ferramentas para compreender uma sociedade que, na Modernidade, emancipa suas diferentes esferas da determinação e dominação da religião e, com isso, passa a ter regras definidas para cada uma dessas esferas. Ora, trata-se aqui de pensar um ator religioso atuando em uma esfera política, a ONU, que tem suas regras institucionais próprias e desvinculadas da dominação religiosa. Sem o poder de determinação nestas instituições, os atores religiosos passam a atuar nestes espaços públicos respeitando as regras estabelecidas e, por meio delas, fazendo o jogo que lhes propicie defender seus próprios interesses. A religião entra na esfera pública como um ator político em disputa por demandas - dentre diversos atores. No caso aqui analisado, foi possível vislumbrar a capacidade de constrangimento que as regras institucionais exercem sobre os atores sociais. A institucionalidade inerente ao cargo de ministra e os constrangimentos das relações internacionais ao posicionamento de um órgão estatal brasileiro conduzem a ministra a uma mudança no teor de seus pronunciamentos quando comparada à sua posição como pastora. 


\section{REFERÊNCIAS BIBLIOGRÁFICAS}

Alves, José Eustáquio Diniz. O voto evangélico garantiu a eleição de Jair Bolsonaro. Instituto Humanitas Unisinos. 01 de novembro de 2018. Disponível em: http://www. ihu.unisinos.br/188-noticias/noticias-2018/584304-o-voto-evangelico-garantiu-aeleicao-de-jair-bolsonaro Acesso em: outubro de 2020.

BAUвÉrot, Jean. A favor de uma sociologia intercultural e histórica da laicidade. Civitas: Revista de Ciências Sociais. Porto Alegre, EDIPUC-RS, vol. 11, n 2, 2011.

BaubÉrot, J. Sécularisation, Laicité, Laicisation. Empan: Prendrelamesure de l'humain. v. 1, n. 90: 31-38, Paris: Eres. 2013.

Blancarte, Roberto. América Latina, entre pluri-confesionalidad y laicidad. Civitas: Revista de Ciências Sociais. Vol. 11, No 2, Porto Alegre, EDIPUCRS, 2011.

Bоввіо, Norberto. Direita e esquerda: razões e significados de uma distinção política. São Paulo, Editora da Universidade Estadual Paulista - UNESP, 1995.

BRAGON, Ranier; SANDER, Letícia. 58\% da propina foi para evangélicos, diz CPI dos Sanguessugas. Folha de São Paulo. Brasília, 12 de agosto de 2006. Disponível em: https://www1.folha.uol.com.br/folha/brasil/ult96u81306.shtml Acesso em: outubro de 2020.

Brasil Sem Aborto. Comunicado sobre o PL 478/2007 (Estatuto do Nascituro). 30 de julho de 2015. Disponível em: https://brasilsemaborto.org/projetos-de-lei/comunicadosobre-o-pl-4782007-estatuto-do-nascituro/ Acesso em: outubro de 2020.

BURITY, Joanildo. El pueblo evangélico: construcción hegemónica, disputas minoritarias y reacción conservadora. Encartes, vol. 3, n. 6, set. 2020 - fev. 2021, pp. 1-35. Disponível em: https://encartesantropologicos.mx/ Acesso em: outubro de 2020.

BuRITY, Joanildo. (2020). Onda conservadora e surgimento da nova direita cristã brasileira? a conjuntura pós-impeachment no Brasil. Ciencias Sociales Y Religión/Ciências Sociais E Religião. N.22, e020015. Disponível em:https://econtents.bc.unicamp.br/ inpec/index.php/csr/article/view/13754 Acesso em: Outubro de 2020.

CAmporez, Patrik. Damares apresenta filha adotiva e diz que não sequestrou ninguém. EPOCA. 21 de maio de 2019. Disponível em: https://epoca.globo.com/damaresapresenta-filha-adotiva-diz-que-nao-sequestrou-ninguem-23682848 Acesso em: outubro de 2020.

CASAnova, José. Public Religions in the modern world. Chicago: The university of Chicago Press, 1994.

Conger, K. The Christian Right in U.S. Politics. Oxford Research Encyclopedia of Politics. Setembro, 2019. Disponível em: https:/oxfordre.com/politics/view/10.1093/ acrefore/9780190228637.001.0001/acrefore-9780190228637-e-810Acesso em: janeiro de 2021. 
DESIDERI, Leonardo. Aliança pela liberdade religiosa une Trump e Bolsonaro; conheça os princípios. Gazeta do Povo. Brasília, o6 de fevereiro de 2020. Disponível em: https:// www.gazetadopovo.com.br/vida-e-cidadania/principios-da-alianca-pela-liberdadereligiosa/ Acesso em: outubro de 2020.

Diário De Pernambuco. "O Estado é laico, mas nosso governo é cristão", diz Bolsonaro no Twitter. 16 de setembro de 2020. Disponível em: https://www.diariodepernambuco. com.br/noticia/politica/2020/o9/o-estado-e-laico-mas-nosso-governo-e-cristaodiz-bolsonaro-no-twit.html Acesso em: outubro de 2020.

Embaixada e Consulados dos EUA no Brasil. Segunda reunião ministerial histórica para promover a liberdade religiosa. 16 de julho de 2019. Disponível em: https:// br.usembassy.gov/pt/segunda-reuniao-ministerial-historica-para-promover-aliberdade-religiosa/ Acesso em: outubro de 2020.

EstadÃo. Eleições 2018; Apuração $1^{0}$ turno. Disponível em: https://politica.estadao.com. br/eleicoes/2018/cobertura-votacao-apuracao/primeiro-turno Acesso em: outubro de 2020.

Exame. Venezuela: Bolsonaro fala sobre "ditadura de Maduro" e rejeita intervenção. 30 de outubro de 2018. Disponível em: https://exame.com/mundo/venezuela-bolsonarofala-sobre-ditadura-de-maduro-e-rejeita-intervencao/ Acesso em: outubro de 2020.

FERreIra, Cynthia. Flores na Marcha pela Vida contra o aborto. Instituto Flores de Aço. 5 de novembro de 2014. Disponível em: http://institutofloresdeaco.blogspot.com/2014/11/ flores-na-marcha-pela-vida-contra-o.html?q=damares Acesso em: outubro de 2020.

FolHa de S.Paulo. No rádio, Bolsonaro associa a Venezuela e Haddad e critica violência. Disponível em: https://www1.folha.uol.com.br/poder/2018/10/no-radio-bolsonaroassocia-pt-a-venezuela-e-haddad-critica-violencia.shtml Acesso em: outubro de 2020.

FonsecA, Alexandre B. Foram os evangélicos que elegeram Bolsonaro? Instituto HumanitasUnisinos. 07 de novembro de 2018. Disponível em: http://www.ihu. unisinos.br/78-noticias/584446-foram-os-evangelicos-que-elegeram-bolsonaro\# Acesso em: outubro de 2020.

Freston: Protestantes e política no Brasil: da Constituinte ao impeachment. (Tese de Doutorado). Universidade Estadual de Campinas. 303 f. São Paulo, Unicamp, 1993.

Governo Brasileiro. Operação Acolhida. Disponível em: https://www.gov.br/acolhida/ historico/ Acesso em: outubro de 2020.

G1. Política. Bolsonaro diz no Conselho de Ética que coronel Ustra é 'herói brasileiro'. Brasília. 08 de novembro de 2016. Disponível em: http://g1.globo.com/politica/ noticia/2016/11/bolsonaro-diz-no-conselho-de-etica-que-coronel-ustra-e-heroibrasileiro.html Acesso em: outubro de 2020. 
G1. Juan Guaidó se declara presidente interino da Venezuela e é reconhecido por Brasil e EUA. 23 de janeiro de 2019. Disponível em: https://g1.globo.com/mundo/ noticia/2019/o1/23/juan-guaido-presta-juramento-como-presidente-interino-davenezuela.ghtml Acesso em: outubro de 2020.

MAIA, Eduardo Lopes Cabral. A Política Evangélica: análise do comportamento da Frente Parlamentar Evangélica na Câmara Federal (2007-2010). (Tese de doutorado). 335 f. Programa de Pós-Graduação em Sociologia Política, Universidade Federal de Santa Catarina. Santa Catariana, UFSC, 2012.

MAIA, Gustavo. Campanha de Bolsonaro associa adversários a Maduro: "quem planta, colhe”. UOL Notícias. São Paulo, 20 de setembro de 2018. Disponível em: https:// noticias.uol.com.br/politica/eleicoes/2018/noticias/2018/o9/20/campanha-debolsonaro-associa-adversarios-a-maduro-para-atrair-votos.htm Acesso em: outubro de 2020.

Mariano, Ricardo; Pierucci, Antonio Flavio. O envolvimento dos pentecostais na eleição de Collor. Novos Estudos Cebrap. São Paulo, nov., 1992 v. 3, n. 34: 92-106.

Mariano, Ricardo. Expansão pentecostal no Brasil: o caso da Igreja Universal. Estudos Avançados. São Paulo, 2004, n. 52, v.18: 121-138.

MARIANo, Ricardo. Laicidade à brasileira: Católicos, pentecostais e laicos em disputa na esfera pública. Civitas: Revista de Ciências Sociais. Porto Alegre, EDIPUCRS, 2011 v. 11, n.2: 238-258.

Mariano, Ricardo. Neopentecostais: sociologia do novo pentecostalismo no Brasil. $5^{\mathrm{o}} \mathrm{ed}$. São Paulo: Edições Loyola, 2014.

Mariano, Ricardo; Gerardi, Dirceu André. (2019). Eleições presidenciais na América Latina em 2018 e ativismo político de evangélicos conservadores. Revista USP. n.120: 61-76. Disponível em: http://www.revistas.usp.br/revusp/article/view/155531/151189 Acesso em: outubro de 2020.

Ministério da Família da Mulher e dos Direitos Humanos. Outubro de 2020. Disponível em: https://www.gov.br/mdh/pt-br Acesso em: outubro de 2020.

Ministério Público Federal. Caso Lava Jato. Disponível em: http://www.mpf.mp.br/ grandes-casos/lava-jato/entenda-o-caso Acesso em: outubro de 2020.

Montero, Paula. Religião, pluralismo e esfera pública no Brasil. Novos Estudos Cebrap. São Paulo, março 2006. n.74: 47-65.

Montero, Paula. Secularização e espaço público: a reinvenção do pluralismo religioso no Brasil. Etnográfica. maio 2009. v.13, n.1, p.7-16.

NovAEs, Regina. A divina política. Notas sobre as relações delicadas entre religião e política. Revista USP. São Paulo, março-maio, 2001 n. 49: 6o-81. 
ONU Mulheres Brasil. Princípios de empoderamento das mulheres. Novembro de 2017. Disponível em: http://www.onumulheres.org.br/wp-content/uploads/2016/o4/ cartilha_ONU_Mulheres_Nov2017_digital.pdf. Acesso em: outubro de 2020.

OtÁvio, Chico. "O Brasil é laico, mas o presidente é cristão", diz Bolsonaro. O Globo. 15 de fevereiro de 2020. Disponível em: https://valor.globo.com/politica/ noticia/2020/02/15/o-brasil-e-laico-mas-o-presidente-e-cristao-diz-bolsonaro. ghtml. Acesso em: outubro de 2020.

Pierucci, Antonio Flavio; Prandi, Reginaldo. Religiões e voto: a eleição presidencial de 1994. Opinião Pública. Campinas, maio 1995. v. 3, n. 1, p.32-63.

Pleyers, Geoffrey. El ascenso político de los actores religiosos conservadores. Cuatro lecciones del caso brasileño. Encartes. v. 3, n. 6, septiembre 2020-febrero 2021, pp. 65-84. Disponível em: https://encartesantropologicos.mx/ Acesso em: outubro de 2020.

PresidÊnCia Da República. Casa civil. Lei n. 12.527. 18 de novembro de 2011. Disponível em: http://www.planalto.gov.br/ccivil_03/_ato2011-2014/2011/lei/l12527.htm Acesso em: outubro de 2020.

Shalders, André. Como Damares Alves saiu de ministra 'periférica' a figura central do bolsonarismo. BBC News Brasil. Brasília, 3 de setembro de 2020. Disponível em: https://www.bbc.com/portuguese/brasil-53980530 Acesso em: outubro de 2020.

TAYLOR, Charles. Uma era secular. Trad. de Nélio Schneider e Luiza Araújo. São Leopoldo: Ed. da Unisinos, 2010.

Tolotti, Rodrigo. Conheça o livro de cabeceira de Jair Bolsonaro: "A verdade sufocada". InfoMoney. 31 de julho de 2018. Disponível em: https://www.infomoney.com.br/ politica/conheca-o-livro-de-cabeceira-de-jair-bolsonaro-a-verdade-sufocada/ Acesso em: outubro de 2020.

Vitorio, Tamires. "Estado é laico, mas ele é cristão”, diz Bolsonaro na Marcha para Jesus. Exame. 20 de junho de 2019. Disponível em: https://exame.com/brasil/o-estado-elaico-mas-ele-e-cristao-diz-bolsonaro-na-marcha-para-jesus/ Acesso em: outubro de 2020.

Weber, Max. "As seitas protestantes e o espírito do capitalismo”. In: Ensaios de Sociologia. $5^{\mathrm{a}}$ ed. Rio de Janeiro: Zahar, 1982.

Weber, Max. A ética protestante e o espírito do capitalismo. São Paulo: Martin Claret, 2001. Weber, Max. Ciência e política: duas vocações. 17 $7^{\mathrm{a}}$ Ed. São Paulo: Cultrix, 2011.

ZEPEDA, José de Jesús Legorreta. Secularizacão ou ressacralização? O debate sociológico contemporâneo sobre a teoria da secularização. Revista Brasileira de Ciências Sociais. São Paulo, jun. 2010. v. 25, n. 73: 129-141.

Recebido: 30/10/2020 | Aprovado: 13/02/2021 